\title{
Lógica: tópicos históricos, la lógica en el Perú
}

\author{
Diógenes Rosales Papa \\ Universidad Ricardo Palma \\ diogenes.rosales@gmail.com
}

\begin{abstract}
RESUMEN
El brevísimo recorrido por la historia de la lógica nos permite anotar los conceptos básicos que tienen como punto partida los Analiticos de Aristóteles, particularmente el silogístico aristotélico. Así, podemos apreciar en Leibniz, Euler, Boole, Frege, Peano y Russell que el hilo conductor es el análisis del silogismo, donde están centradas las nociones de inferencia, proposición, verdad-validez, lenguaje-objeto y metalenguaje, y particularmente el concepto de cálculo lógico. En este cálculo, los temas centrales son la lógica proposicional y la lógica de predicados de primer orden. En esta línea, Francisco Miró Quesada Cantuarias, introdujo por primera vez la enseñanza de la lógica en el Perú e Iberoamérica. Los temas están en su libro Lógica (1946), y más completo en Lógica 1: filosofía de las matemáticas (1980). Entre otros exponentes, fueron relevantes en la difusión de la lógica, Juan B. Ferro Porcile, Walter Redmond y Carlos Cifuentes.
\end{abstract}

Palabras clave: Aristóteles, silogismo, Leibniz, proposición, inferencia, Francisco Miró Quesada Cantuarias.

\section{Logic: historical topics, the logic in Peru}

\begin{abstract}
The brief journey of logic through history allows us to register the basic concepts that have The Aristotle's Analytics as a starting point, particularly the Aristotelian syllogistic. Thus, we can appreciate an analysis of the syllogism thread between Leibniz, Euler, Boole, Frege, Peano and Russell, where the notions of inference, proposition, truth-validity, language-object and metalanguage are focused, and especially the concept of logical calculation. In this calculation, the central themes are the propositional logic and the logic of predicates of the first order. In this sense, and for the first time, the philosopher José Francisco Miró Quesada Cantuarias introduced the teaching of logic in Peru and Latin America. We can see these topics in his book Logic (1946), and in more detail in Logic 1: Philosophy of Mathematics (1980). Juan B. Ferro Porcile, Walter Redmond \& Carlos Cifuentes were other relevant exponents in the dissemination of logic.
\end{abstract}

KeYwords: Aristotle, syllogism, Leibniz, proposition, inference, Francisco Miró Quesada Cantuarias. 


\section{Aristóteles y la lógica griega}

Aristóteles ${ }^{1}$ es considerado el creador del primer sistema lógico, así como sus predecesores contribuyeron al nacimiento de la misma, pues desarrollaron y cultivaron un tipo de discurso que incluía la inferencia y la prueba. Asimismo, en las controversias forenses posiblemente se usaron argumentos con el objeto de refutar la tesis del interlocutor, de forma que los oradores y los filósofos experimentados, por ganar una discusión, estuvieron tentados a recurrir a argumentos falaces y confusos. Consecuentemente, entre los siglos v y IV a. C. los argumentos falaces adquirieron interés especial. Así, una prueba en filosofía parecía oponerse al sentido común, un ejemplo de ello es la doctrina de Parménides, la cual concebía la realidad como una e indivisible, sin limitaciones y sin nacimiento ni muerte: «El ser es y el no ser no es, puesto que si el ser es, no puede no ser, y si el no ser no es no puede ser, puesto no es». Al respecto, la tesis opuesta al inmovilismo de Parménides es la del movimiento sustentado por Heráclito: «Todo fluye, todo cambia, nada es estático» (Mondolfo 1964, pp. 47, 78 y 79).

Además, la inferencia y la prueba incluían el estudio del lenguaje, su sintaxis y su semántica. En este campo, Protágoras se habría interesado en el uso correcto de las palabras e indicó que los términos se refieren a súplicas, preguntas, respuestas y mandatos; mientras que en el plano sintáctico, en el Sofista de Platón, se distingue los nombres de los verbos. Según Platón, una proposición no solamente puede ser verbo o nombre, sino que la forma de esta misma requiere de un nombre y un verbo, lo que significaría que una proposición requiere de una verdad o falsedad. En ese sentido, ya en Platón aparece un programa sobre método axiomático que sería completado por Aristóteles y después más rigurosamente por Euclides.

Sin embargo, a pesar de todos los avances de la lógica hechos por sus predecesores, ello no está a la altura de la genialidad desarrollada por Aristóteles, pues este brilla tanto que opaca a todos los de su época. Como es sabido, los tratados lógicos de Aristóteles están reunidos en el $\operatorname{Organon}^{2}$ (instrumento de la filosofía), el cual presenta los siguientes contenidos: 1) Las categorías, o sobre los predicados del 'ser', o la elaboración de las formas proposicionales. 2) De la proposición, o sobre la proposición de por qué el pensamiento se comunica mediante la proposición, donde se analizan las distintas relaciones entre las proposiciones, así como las conversiones, observaciones y oposiciones. 3) Los analíticos (primeros y segundos), el que contiene el silogismo, tema muy original y el tratado más importante de la lógica aristotélica. A su vez, dentro de los analíticos primeros se desarrolla la teorización del silogismo, mientras que en los analíticos segundos se introduce, por primera vez en la historia de la lógica, el método de la prueba o la demos-

1 Aristóteles nació en Estagira a fines del 384 a. C.

2 Se atribuye a Andrónico de Rodas la clasificación de las obras de Aristóteles, posiblemente usó Organon para los tratados de lógica. 
tración del silogismo, para lo cual emplea el método axiomático. 4) Los tópicos (ocho libros), los cuales tratan sobre el razonamiento dialéctico y probable. 5) Finalmente, Las refutaciones sofísticas, que versa sobre los sofismas o el argumento falaz.

Tiempo después, posteriormente a la muerte de Aristóteles, Teofrasto y Eudemo continuaron con el desarrollo de la lógica. Así, según fuente de Alejandro de Afrodisia, Teofrasto habría desarrollado una teoría del silogismo totalmente hipotético, la que se reduce a las siguientes tres figuras:

Primera figura: Si A entonces B; si B entonces C, por lo tanto si A entonces C.

Segunda figura: Si A entonces B; si no-A entonces C, por lo tanto si no-B entonces C.

Tercera figura: Si A entonces C; si B entonces no-C, por lo tanto, si A entonces no-B.

Estos silogismos hipotéticos abrían nuevos caminos en la lógica, pues las leyes que lo hacen válidos pertenecen a la lógica proposicional. Finalmente, también es importante señalar que Teofrasto habría desarrollado la lógica modal aristotélica.

Por su parte, los megáricos y estoicos desarrollaron la lógica de proposiciones, interpretaron semánticamente y consideraron que las proposiciones pueden ser o verdaderas o falsas, de modo que así introdujeron el principio de bivalencia. A su vez, los estoicos usaron modelos de inferencias que dieron origen a los principios conocidos como modus ponens, modus tollens, la incompatibilidad, tollendo ponens (SD) y ponendo tollens. Entre los megáricos y estoicos sobresalieron Diodoro Cronos y Filón de Megara, quienes estudiaron la lógica de proposiciones y los principios lógicos. Luego, entre los siglos I y vi d. C., fue relevante la lógica de comentarios; gracias a los comentaristas de Aristóteles, la lógica griega fue transmitida a los árabes. Finalmente, entre los siglos XI y xv, la lógica medieval europea fue desarrollada en las escuelas y universidades, donde se enseńó la lógica en la línea formal y lingüística (Prior 1976; Kneale W. y M. 1972; Bochenski 1967).

\section{La lógica moderna}

Leibniz (1646-1716) fue el más grande representante de la lógica moderna en el siglo XVII, investigó la silogística aristotélica y el formalismo de esta lógica le permitió escribir Dissertatio de Arte Combinatoria. A su vez, en sus demostraciones usó el método de la Reducción al Absurdo. Al seguir a Crisipo propuso la teoría de las combinaciones, donde el problema consistía en saber cuántos predicados pueden ser afirmados con verdad de un sujeto dado o cuántos sujetos pueden ser puestos bajo un predicado dado. Por otra parte, Leibniz buscó un lenguaje universal lógicamente construido, lo que le permitió descubrir que tanto las partículas como las conectivas y las preposiciones tienen 
una función importante en la estructura lingüística, de forma que pudo avizorar las funciones de verdad para las conectivas. Al respecto de Aristóteles, Leibinz consideró que este había escrito en su lógica una matemática fuera de su matemática. Asimismo, fue el primero en desarrollar la deducción lógica como puro cálculo, cuya idea está en la Mathesis universales, la cual consistió en usar la forma lógica para las operaciones mecánicas e inequívocas que sirvieran de soporte a la intuición y como ayuda para solucionar controversias. De este modo, Leibniz propone la estructura del cálculo, hoy considerada lógica matemática.

Entre otros grandes representantes podemos citar a Euler (1707-1783) por sus interpretaciones geométricas de la silogística aristotélica. Las proposiciones categóricas fueron representadas en los diagramas de Euler como relaciones entre clases: la proposición categórica universal afirmativa se interpretó como inclusión de clase, mientras que la universal negativa como exclusión de clase y las dos particulares como intersección entre clases. Los diagramas de Euler se constituyeron como procedimientos decisorios para analizar la validez o invalidez de los silogismos.

Entretanto, el sello más importante de la lógica moderna lo encontramos en Boole, quien ideó el álgebra simbólica interpretando algebraicamente las cuatro proposiciones categóricas aristotélicas. Además, reveló por primera vez la afinidad entre la lógica de clases y el cálculo de proposiciones. Boole usó 1 y 0 en vez de verdadero y falso para construir la función lógica y su relación con el álgebra. En suma, construyó un cálculo puramente algebraico mediante símbolos y operaciones definidas; de forma que tradujo la lógica aristotélica, particularmente los silogismos, solo a ecuaciones. Visto así, retomó la lógica de proposiciones al interpretarlo algebraicamente. Sin embargo, Boole, así como Aristóteles, tampoco logró construir definitivamente la lógica matemática.

La lógica adquiere su más alto grado de abstracción con Frege, Peano y Russell, con los cuales el formalismo usado en la lógica antigua y por los escolásticos pasa a ser el principio general de esta y da lugar a la construcción de la lógica como un cálculo, es decir, al uso de un lenguaje artificial. Junto con este lenguaje aparece el afán de determinar un procedimiento decisorio riguroso. $\mathrm{Al}$ respecto, el uso de procedimientos ha aparecido a lo largo del desarrollo histórico de la lógica, pues ya con Aristóteles existían las reglas para decidir la validez de los silogismos. Así, el objetivo de Frege y Peano es encontrar un método, el cual se concreta finalmente en Principia Mathematica de Russell y Whitehead, donde el rumbo de la lógica avizora investigaciones de un trabajo simbólico y al establecimiento de los fundamentos de la matemática. Sobre este punto, en la historia de la lógica según Bochenski (1967), el Begriffsschrift de Frege solo puede ser comparado con los Primeros Analíticos de Aristóteles. De esta forma, Frege es el primero en formular de manera clara y concreta, entre variable y constante, el concepto de función lógica, la idea de función 
de varios argumentos y el concepto de cuantificador; y además es quien formula con mayor rigor lo que es un sistema axiomático, pues distingue entre ley y regla, y entre lenguaje y metalenguaje. Adicionalmente, Frege inició la teoría de las descripciones y elaboró sistemáticamente el concepto acerca del valor de verdad, por lo que se dice que con él empieza la segunda etapa de la lógica matemática, consistente en la búsqueda rigurosa de la demostración exacta que someta a examen crítico a las propias demostraciones de la matemática.

Por su parte, Peano (1858-1932) contribuyó en darle mayor importancia la lógica proposicional y además formuló gran parte de la teoría matemática con todo el criterio de rigor y precisión. Este filósofo concibió la nueva lógica como un poderoso instrumento para la sistematización rigurosa del saber matemático y en la lógica proposicional creó un simbolismo simplificado y preciso. Así, de manera precisa, mostró la aplicación de ese nuevo instrumento en la sistematización de la matemática. Del mismo modo, también es importante la reestructuración de la aritmética, conocida como la 'aritmética de Peano', basada en los conceptos de 'número', 'cero' y 'sucesor', la cual aparece plasmada en los 5 axiomas siguientes: 1) '0 es un número', 2) 'el sucesor de todo número es un número', 3) 'no hay dos números que tengan el mismo sucesor', 4) '0 no es sucesor de ningún número' y 5) 'toda clase que contiene 0 y que contiene el sucesor de $n$ siempre que contenga $n$ incluye la clase de números' (Prior 1976, p. 189).

En este proceso del desarrollo de la lógica, Russell tiene las mismas ideas que Frege acerca del problema de las relaciones entre matemática y lógica, también compartidas por Peano, es decir, la construcción de la matemática a partir de la lógica, una deducción de la matemática a partir de la lógica. Este proyecto aparece plasmado en Principia Mathematica, 3 volúmenes, (1910-1913), escrita en colaboración con su maestro Whitehead. En esta obra se expone — después de una discusión sobre la naturaleza de la lógica y la matemática, y sus relaciones recíprocas y otras semejantes- el cálculo proposicional, la teoría de las proposiciones con variables, el álgebra de clases y la de relaciones; finalmente, se trata sobre la cardinalidad y fundamentos de la aritmética.

Este breve recorrido por la historia de la lógica nos permite anotar sus conceptos básicos, los cuales tienen su punto partida en los Analíticos de Aristóteles, especialmente en la silogística aristotélica. Así, podemos apreciar en Leibniz, Euler, Boole, Frege, Peano y Russell que el hilo conductor es el análisis del silogismo, donde están centradas las nociones de inferencia, proposición, verdad-validez, lenguaje-objeto y metalenguaje, y particularmente el concepto de cálculo lógico; en este cálculo, los temas centrales son la lógica proposicional y la lógica de predicados de primer orden. 


\section{La lógica en el Perú}

Siguiendo la línea de Principia Mathematica de Russell-Whitehead, Francisco Miró Quesada Cantuarias (FMQC) ${ }^{3}$ introdujo por primera vez la lógica matemática en la enseñanza universitaria del Perú e Iberoamérica, los temas están en su libro Lógica (1946). Pedagógicamente, divide el estudio de la lógica en tres partes, en la primera trata la lógica descriptiva donde se introducen las nociones básicas sobre el concepto, juicio y el raciocinio. La segunda contiene la lógica matemática, la cual desarrolla la lógica proposicional, lógica cuantificacional y la lógica de clases. A su vez, desde el punto de vista de la filosofía de la lógica, la tercera parte aborda los problemas fundamentales de la mis$\mathrm{ma}$, por ejemplo, la fundamentación de los principios lógicos, de los sistemas lógicos y el problema de la definición (Rosales, 2002, pp. 1087-1105). Visto así, el estudio de la lógica se difunde en el Perú como parte del programa de educación secundaria que se impartía a los alumnos del quinto año (curso de Filosofía y Lógica) ${ }^{4}$. Incluso ahora, aún existen colegios donde se imparten el curso de Filosofía y Lógica. Adicionalmente, en la Universidad Nacional Mayor de San Marcos circularon los textos Iniciación lógica, e Introducción a la lógica y a la teoría de conjuntos de FMQC, especialmente para alumnos de los cursos básicos.

Sin embargo, el texto de lógica más completo de FMQC (1980) es Lógica 1: filosofia de las matemáticas, contiene temas de lógica planteados para distintos grados de la enseñanza. La virtud de este libro es comparable solo con las producciones más serias hechas en otros países sobre la materia. De este modo, los contenidos de la lógica son explicados de manera más amplia y completa; entre ellas, la lógica como teoría de la deducción introduce el lenguaje de la lógica proposicional, hace un análisis intuitivo del concepto de deducción, presenta los distintos tipos de la lógica coligativa y aborda el método axiomático y el teorema de la deducción. Asimismo, en la lógica de primer orden se tratan los conceptos básicos, la interpretación de los lenguajes y los métodos de deducción formal de primer orden, se concluye con las demostraciones de los distintos casos del teorema de la deducción. Como es visible, nuestro lógico considera de suma importancia la investigación lógica y matemática, especialmente la investigación metateórica.

FMQC (1992), como estudioso de la filosofía y la lógica, se propuso un programa del conocimiento del mundo en el siguiente orden: "primero, esclarecer la naturaleza de la lógica, luego la de la matemática; una vez hecho esto, pasar a las ciencias empíricas, siempre por orden de presuposición, la física en sentido amplio, la biología, las ciencias sociales" (pp. 3-11). El tema central de su programa es encontrar la estructura interna

3 Francisco Miró Quesada Cantuarias, Lima 1918, fue titular de la cátedra de Lógica entre 1946 y 1970 de la Universidad Nacional Mayor de San Marcos.

4 Miró Quesada, F. Lógica. Texto escolar; y Augusto Salazar Bondy. Filosofía. Texto escolar 
de la razón como fundamento del conocimiento con principios de validez universal y necesaria, principios que nos permitirían explicar tanto la lógica matemática como los otros conocimientos. Miró Quesada encontró los principios en las coincidencias y las compatibilidades de las relaciones formales de la lógica y la matemática, cuyas diferencias podían explicarse racionalmente. Por otra parte, "si me preguntasen quién es Francisco Miró Quesada C., yo diría muy serio que él es, sobre todo, un mago eternamente joven, enamorado de la razón". Newton Da Costa (1992) agradece así por el término paraconsistente ${ }^{5}$, sugerido por el peruano para su teoría lógica, entonces en construcción.

Por la proliferación de lógicas, FMQC (1978) distingue las dos grandes regiones, la lógica clásica y las lógicas no clásicas. Precisamente, sustenta las características de la lógica clásica considerando que esta posee un lenguaje formal característico, que es asertórico, y tiene su fundamento en los tres principios clásicos (identidad, no contradicción y tercio excluido). Respecto a las lógicas no clásicas señala que estas se caracterizan por carecer de una de las características de la lógica clásica: o no es asertórica, o no posee un lenguaje formal característico, o carece de uno de los tres principios lógicos.

Aparte de su amplia producción filosófica, política y periodística, cabe mencionar al respecto de la contribución de Miró Quesada a la lógica académica lo siguiente: Sobre una definición de la lógica en Dianoia (México, FCE, 1955, pp. 261-291); Modelo lógico-matemático, en Mondes en Développement (París, Nº 7,1974, pp. 87-98); Sobre el concepto de razón, en Revista latinoamericano de filosofía (Buenos Aires, Vol I, $\mathrm{N}^{\circ}$ 3, 1975, pp. 183-191); Lógica de primer orden sin variables, en Lógica (Lima, Fondo editorial PUCP, 1976, pp. 29-47); La filosofía de N. C. A. Da Costa, en Crítica (México, 1983, pp. 65-85), etc. Respecto a la lógica deóntica, Miró Quesada consideró kantianamente que el hombre no debe ser un medio, sino un fin, por lo que la acción racional no debe ser arbitraria.

Posteriormente, Juan B. Ferro Porcile (Lima, 1920-1993), sucesor de Francisco Miró Quesada en la cátedra de Lógica de San Marcos, ejerció gran influencia en la formación de docentes a partir de la década de 1960. Su obra Procedimientos decisorios para fórmulas monádicas de primer grado marca un hito en la historia de la lógica en Latinoamérica. En tanto teoría de las inferencias, la lógica tiene el objetivo principal de establecer la validez o invalidez de las mismas mediante un procedimiento decisorio que ha ser mecánico, efectivo y general. Para arribar a este, Ferro estudia y analiza ventajas y desventajas de los procedimientos de Löwenhein, Skolem y Behmann, Bernays y Schönfinkel, Quine, von Wrigth y Kleene. En vista de que estos procedimientos resultan operativamente engorrosos o incompletos, Ferro emplea la demostración de Herbrand para postular un procedimiento decisorio al que llamó Método FH (Ferro-

5 La lógica paraconsistente es una de las lógicas no clásicas creado por Newton Da Costa. 
Herbrand), el cual reduce cualquier fórmula de la lógica cuantificacional de primer grado a una forma normal, con obvias ventajas pedagógicas en cuanto a percepción de la validez o invalidez de una fórmula. Este método se generalizó, especialmente en la decisión de validez o invalidez, para fórmulas monádicas de primer grado (Rosales 1995).

Ulteriormente, en la década de 1970, Walter Redmond O’Toole enseñó lógica formal en la Universidad Nacional de San Marcos y en la Pontificia Universidad Católica del Perú, mientras realizaba simultáneamente una investigación sobre la lógica en el Virreinato del Perú. En ella, Redmond estudió la Philosophia thomistica de Juan de Espinoza Medrano, el Lunarejo, en comparación con los Elementa Philosophiae de Isidoro de Celis. El cotejo de ambas visiones de la lógica nos permite entender las diferencias entre los filósofos americanos del siglo XVII, anteriores a la modernidad, y aquellos de la segunda mitad del siglo XvIII, conscientes de las revoluciones de la filosofía y la ciencia llevadas a cabo por Galileo, Bacon y Descartes. El análisis de su trabajo estuvo centrado en el campo de la lógica formal (Redmond 1998).

A su vez, Diógenes Rosales Papa compartió la cátedra de Lógica con Juan B. Ferro y posteriormente fue titular de la cátedra de Lógica de la Universidad Nacional Mayor de San Marcos, entre 1970 y 1998. Actualmente, es profesor de Lógica y Epistemología en la Pontificia Universidad Católica del Perú (desde 1970) y de la Universidad Ricardo Palma (desde 2006). Asimismo, ha impartido el curso de Lógica en los distintos niveles de la enseñanza, para profesores de Educación Secundaria en el área de Filosofía y Lógica. Como docente universitario (Universidad Inca Garcilaso de la Vega, Universidad del Sagrado Corazón, Universidad del Pacífico) ha desarrollado los temas tradicionales de la lógica, lógica proposicional y lógica de predicados de primer orden, contenidos en los libros Introducción a la lógica (Lima, Ed. Monterrico, 1994) e Introducción a la lógica (coautor O. Trelles, Lima, Fondo Editorial PUCP, 2000).

Visto así, es fácil ver la evolución de la lógica en el Perú por el contenido temático de los programas de Lógica comparados con los que se dictan en diversas universidades del extranjero, de modo que los temas que desarrollamos son comunes tanto en las universidades americanas como en las europeas (la teoría de la argumentación, los problemas metateóricos, los diagramas semánticos, el método de la deducción natural (Rosales 1994, 2000).

Por otro lado, en la década del 80, José Carlos Cifuentes (1992, 1995, 1996, 1999, 2003, 2010) fue profesor de Lógica de la Pontificia Universidad Católica del Perú, actualmente es profesor en el Departamento de Matemática de la Universidad Federal de Paraná, Brasil. La contribución de Cifuentes consiste en haber introducido los diagramas semánticos en el sílabo, de forma que se pudo apreciar la ventaja pedagógica en el análisis de validez tanto para fórmulas proposicionales como cuantificacionales. Además de ello, Carlos Cifuentes desarrolló la lógica en el nivel superior de abstracción. Entre sus investigaciones más relevantes en la lógica fuzzy de Zadeh, se encargó de ge- 
neralizar la lógica y la teoría de conjuntos clásicos a un número arbitrario de valores de verdad. La lógica fuzzy, en sus aspectos topológicos, es discutida en los artículos Is There Logic Behind Fuzziness? y A Topological Approach to the Logic Underliyng Fuzzy Subset Theory. Asimismo, también trató la teoría de modelos para lenguajes de primer orden, segundo orden e infinitarios, desde un punto de vista no tradicional en el libro El método de los isomorfismos parciales: un estudio de la expresabilidad matemática y en el artículo Cauchy Completeness in Elementary Logic. Posteriormente, propuso una nueva visión de la teoría de modelos de lenguajes de primer orden usando nociones provenientes de la topología. Asimismo, en la epistemología de la matemática discutió la posibilidad de un conocimiento estético al interior de la matemática, donde la parte esencial de este conocimiento está asociado tanto a un objeto matemático, como a la simplicidad de un razonamiento del mismo carácter.

$\mathrm{Al}$ respecto de la actualización de los programas y la difusión de la Lógica, ello ha sido parte de la preocupación de Oscar Trelles Montero (2001), profesor de Lógica y director del Taller de Lógica de la Pontificia Universidad Católica del Perú, quien considera importante la comprensión del por qué de las operaciones lógicas para que sea un trabajo de reflexión en vez de un procedimiento puramente mecánico. Sus obras más importantes son Apuntes de lógica modal Introducción a la lógica (Trelles y Rosales 2000). En el primer texto enfoca la lógica modal desde la semántica tomando los diagramas de Hughes y Cresswell y aplicadolo a la lógica temporal y deóntica; desde la sintaxis usa el método de deducción natural, expuesto en Introducción a la lógica. Por otro lado, en el segundo texto trata el método de los diagramas semánticos para la lógica proposicional y lógica cuantificacional.

Finalmente, por su amplia experiencia en la docencia universitaria, intervenciones en congresos nacionales e internacionales, Luis Piscoya Hermoza (1978) ha contribuido en la lógica con su texto Lógica, así como también ha desarrollado la Aplicación de la lógica proposicional a la teoría elemental de la probabilidad en lógica: aspectos formales y filosóficos. Por su parte, el profesor Marino Llanos Villajuán (2003), en el contexto de la lógica clásica, ha estudiado los elementos de la lógica proposicional y la lógica de primer orden para establecer una analogía con la lógica jurídica, la aplicación a la prueba judicial y la detección de las falacias en la argumentación jurídica. Asimismo, también son dignos de mención los textos de Bernardo Rea Ravello (1981) y de Enrique L. Dóriga (1986), este último fue profesor de la Universidad del Pacífico. 


\section{Referencias}

Bochenski, J. (1967). Historia de la lógica fomal. Madrid: Gredos.

Cifuentes, J. C., y Carnielli, W. A. (1995). Is There Logic Behind Fuzziness? (Conf). Proc. of the X Conference on Mathematical Logic (Itatiaia-Río de Janeiro). Colección CLEUNICAMP, Vol. 14, 1995, pp. 73-91.

Cifuentes, J. C. (1992). El método de los isomorfismos parciales: Un estudio de la expresabilidad matemática (en portugués). Vol. 10, Colección CLE-UNICAMP. 223 fs.

Cifuentes, J. C. (1999). A Topological Approach to the Logic Underliyng Fuzzy Subset Theory. AMS Contemporary Mathematics. 235, 53-62.

Cifuentes, J. C. (2003). Fundamentos estéticos de la matemática: De la habilidad a la sensibilidad (en portugués). En M.A.V. Bicudo (Org.), Filosofía de la educación matemática: Concepciones y movimiento (pp. 59-79) Brasilia, Brasil: Editora Plano.

Cifuentes, J. C. (2010). Del conocimiento matemático a la educación matemática: Una «odisea espiritual» (en portugués). En S. M. Clareto, A. R. Detoni y R. M. Paulo (Orgs.), Filosofía, matemática y educación matemática: comprensiones dialogadas (pp. 13-32). Juiz de Fora-Brasil: Editora de la UFJF.

Cifuentes, J. C., Zette, A. M. y Mundici, D. (1996). Cauchy Completeness in Elementary Logic. The Journal of Symbolic Logic. 61 (4), 1153-1157.

DóRIga, E. L. (1986). Metodología del pensamiento (la lógica desde el hombre primitivo hasta la informática). Barcelona: Herder.

Da Costa, N. (1992). La filosofía de la lógica de Francisco Miró Quesada Cantuarias. En David Sobrevilla y Domingo García Belaunde (Eds.), Lógica, razón y humanismo (pp. 69-78). Lima.

Ferro, J. B. (1966). Procedimientos decisorios para fórmulas monádicas de primer grado. Tesis doctoral. Lima: Universidad Nacional Mayor de San Marcos.

Kneale, W. y Kneale, M. (1972). El desarrollo de la lógica. Madrid: Tecnos.

Llanos, M. (2003). Lógica jurídica. Lima: Universidad Nacional Mayor de San Marcos, Instituto de Investigaciones Humanísticas.

Miró Quesada, F. (1946). Lógica. Lima: Librería e imprenta D. Miranda. Biblioteca de la Sociedad Peruana de Filosofía.

Miró Quesada, F. (1978). Las lógicas heterodoxas y el problema de la unidad de la lógica. En Diógenes Rosales (Ed.), Lógica: Aspectos formales y filosóficos (pp. 13-43). Lima: Pontificia Universidad Católica del Perú, Fondo Editorial.

Miró Quesada, F. (1980). Lógica 1: filosofía de las matemáticas. Lima: Ignacio Prado Pastor, Ed. Miró Quesada, F. (1992). Bosquejo autobiográfico. En David Sobrevilla y Domingo García Belaunde (Eds.), Lógica, razón y humanismo (pp. 3-11). Lima: ...

Mondolfo, R. (1964). El pensamiento antiguo. 5a ed. T. I. Buenos Aires: Losada. 
Piscoya Hermoza, L. (1978). Aplicación de la lógica proposicional a la teoría elemental de la probabilidad. En Diógenes Rosales (Ed.), Lógica: Aspectos formales y filosóficos (pp. 59-69). Lima: Pontificia Universidad Católica del Perú, Fondo Editorial.

Piscoya Hermoza, L. (1997). Lógica. Lima: Universidad Nacional Mayor de San Marcos.

Prior, A. (1976). Historia de la lógica. Madrid: Tecnos.

Rea Ravello, B. (1981). Introducción a la lógica. Lima: Amaru Editores.

Redmond, W. (1998). La lógica en el virreinato del Perú. Lima: Fondo de Cultura Económica, Instituto Riva-Agüero, Pontificia Universidad Católica del Perú.

Rosales, D. (1995). Ferro y los procedimientos decisorios de la lógica. Areté. Revista de filosofía. VII (2), 227-243. Lima, Pontificia Universidad Católica del Perú.

Rosales, D. (2000). Lógica: La argumentación como lógica del pensamiento natural. Lima: Textos EUDED, Universidad Nacional Federico Villarreal, 2000.,

Rosales, D. (2000). El concepto de verdad en los procedimientos decisorios de la lógica. En Miguel Giusti (Ed.), La filosofía del siglo XX: balance y perspectivas (Actas del VII Congreso Nacional de Filosofía) (pp. 545-550). Lima: Pontificia Universidad Católica del Perú, Fondo Editorial.

Rosales, D. (2002). Francisco Miró Quesada y la difusión de la lógica en el Perú. En Margarita Guerra Matinière, Oswaldo Holguín Callo y César Gutiérrez Muñoz (Eds.), Sobre el Perú (Homenaje a José Agustín de la Puente Candamo) (pp. 1087-1105). Lima: Universidad Católica del Perú, Fondo Editorial, Facultad de Letras y Ciencias Humanas.

Rosales, D. (2011). ¿La lógica epistémica, es solo consistente? En Pablo Quintanilla y Diógenes Rosales (Eds.). Tolerancia (pp. 249-264), IV vol. Lima: Pontificia Universidad Católica del Perú, Fondo Editorial.

Rosales, D. y García, S. (1994). Filosofía y lógica. 9a Ed. Lima: Editorial Monterrico.

Trelles, Ó. (2001). Apuntes de lógica modal. Lima: Pontificia Universidad Católica del Perú, Fondo Editorial. 